\title{
Application of Relevance Theory in College English Teaching
}

\author{
Zhao Shuo ${ }^{1,2,{ }^{*}, \text { Dou Chen }}{ }^{1}$ \\ ${ }^{1}$ School of Foreign Studies, Northwestern Polytechnical University, Xi'an, China \\ ${ }^{2}$ School of Foreign Studies, Xi' an University, Xi'an, China
}

Email address:

zhaoshuo@nwpu.edu.cn (Zhao Shuo),476448325@qq.com (Dou Chen)

${ }^{*}$ Corresponding author

\section{To cite this article:}

Zhao Shuo, Dou Chen. Application of Relevance Theory in College English Teaching. Education Journals. Vol. 7, No. 5, 2018 , pp. $132-135$. doi: $10.11648 /$ j.edu.20180705.15

Received: October 8, 2018; Accepted: November 1, 2018; Published: November 8, 2018

\begin{abstract}
In coming society of new era English has become the communicative language of today's international context. More and more people are using English to obtain and exchange information. First English reading, as an important part of English, is one of the ways to reflect the reader's potential English communication skills. The reading process links authors and readers in two ways. On the one hand, the author expresses his intentions, thoughts and feelings in written form. On the other hand, the reader understands the information to be expressed by the author through the identification, connection and reasoning of these linguistic symbols. Over the years English teachers have been dedicated to improving students' comprehensive reading skills. However there are quite a few English teachers who pay much attention to vocabulary, sentences, paragraphs and articles in various reading skills to train students, let alone from the perspective of relevance theory. Then the paper aims to discuss and analyze the cognitive nature of English reading, comprehensively discusses three reading patterns. Hence English reading comprehension requires a more comprehensive and effective reading mode to guide its teaching and learning. Relevance theory holds that reading is the process of explicit reasoning, the process of readers looking for the best association, and the process of choosing context. Therefore teachers will focus on cultivating students' reasoning ability, focusing on dynamic context and finding relevance. At last the paper puts forwards several points of relevance theory and attempts to find effective solutions to apply them in the reading process.
\end{abstract}

Keywords: Relevance Theory, College English Reading, Application

\section{Introduction}

\subsection{Research Background}

Reading comprehension has always been an important way to obtain information in our lives, and it plays an important role in college English teaching [2,3]. Reading is important for language learning because readers can obtain language information from the materials they read. Reading is recognized as one of the most important ways to obtain information in life and foreign language learning [6]. Reading comprehension requires readers to use their own linguistic and cultural knowledge to effectively analyze and reason about reading materials [9].

Relevance theory is a theory that attempts to explore human discourse understanding and communication from a cognitive perspective. Recently more and more researchers have used it to explore English teaching.

\subsection{Significance of the Study}

Under the guidance of relevance theory, the paper explores a more effective mode of college English reading teaching, which has a realistic guiding significance to improve the current college English teaching and to help college students improve their English reading level.

\section{Literature Review}

\subsection{Overview of Reading Comprehension}

Reading is the one of very important ways of acquiring information and exchanging information for foreign language 
learners. As Krashen once mentioned reading is helpful to acquire a new language [1].

The improvement of reading comprehension for Chinese students' learning English have been greatly concerned by English teachers for quite a long time, and they wish to have effective strategies for improving their reading comprehension as soon as possible [4]. The research made by Widdowson indicates that reading comprehension is kind of reasoning activity.

Liu Zhenqian \& Thomas G. Bever studied from the perspective of cognitive linguistics and believed that language understanding is fundamentally the discovery of the main units of meaning [8]. His experimental research proves that syntactic analysis plays an important role in the reading of foreign language learners. From an intercultural perspective, Liao Daosheng believes that cultural barriers are one of the main obstacles for Chinese students to read English [5]. Language learning can be achieved with the right level of reading input [7].

\subsection{The Traditional Three Modes of Reading Comprehension}

\subsubsection{Bottom-up Reading Model}

According to the result of our survey it has been found that nowadays most of the students begin their English reading with interpreting the meaning of new words. That is to say, most of the college students are likely to read a text in the bottom-up reading model. In this model readers usually process a text from the lowest level to the highest level.

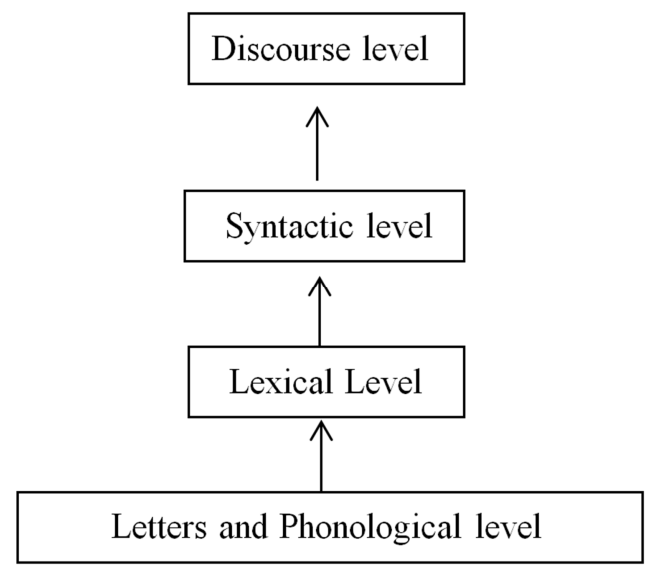

Figure 1. Bottom-up Processing Sequence in Reading.

In the course of bottom-up reading, if the readers know the function and these different kinds of cohesive devices very well, it will be easier for them to make clear the relationship among sentences and relationship among passages.

To conclude, in the bottom-up reading model, readers should learn to search for relevance among words, relevance among sentences and relevance among paragraphs with the help of cue words and topic sentences, especially when there are too many new words and long sentences appearing in the text.

\subsubsection{Top-down Reading Model}

This model begins processing a text from a higher level to a lower level.

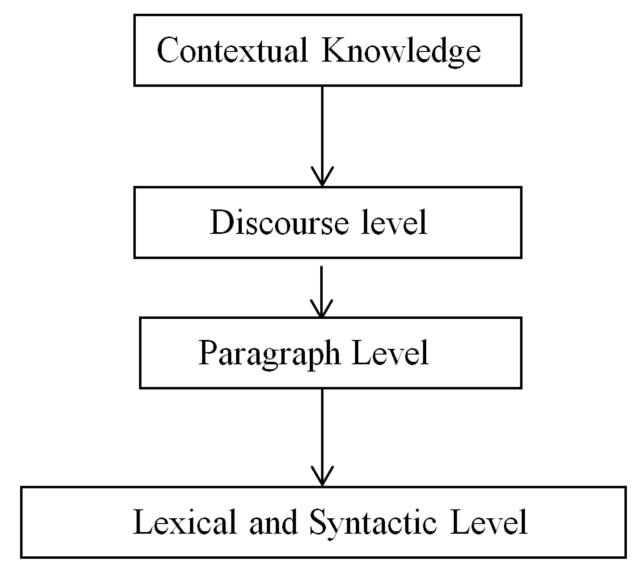

Figure 2. Top-down Reading Model.

The understanding of the overall meaning of the paper is the primary goal of reading comprehension relative to the mastery of the word. In this theory, reading is a constructive process that can be reasoned. Readers can quickly sweep through the surface meaning and go directly into the deep structure of the discourse. The research made by linguist Grellet shows that the content provided by the reader for the reading task in the top-down reading model is more useful and effective than the content provided by the bottom-up reading model.

\subsubsection{Interactive Reading Model}

According to Relevance Theory, human communication is an ostensive-inferential process, a process of searching for the optimal relevance. In the course of English reading, to search out optimal relevance is the ultimate goal.

The above model means that readers can obtain information from multiple sources. They use the information at the same time. The information interacts with each other. Reader does not need to follow any mode and selectively use the information for understanding purposes. These channels include semantics, vocabulary, icons, syntax, logos and phonology.

\subsection{Overview of Relevance Theory}

Relevance theory is the theory of cognitive pragmatics proposed by Sperber and Wilson 1986. In the book Relevance: Cognition and Communication, Sperber and Wilson discuss the nature of communication [10].

After the emergence of relevance theory in thirty years, it is still active in the mainstream camp of international pragmatics research [11]. According to the relevance theory, relevance is the nature of human cognition [12]. It occurs while reading starts. Readers with different language backgrounds will have different relevance. Only when the author and the reader make correct assumptions about each other's cognitive abilities and background knowledge, and choose a sentence style that suits each other, can the two parties achieve smooth communication. Readers with the same language background will have different relevance too. Of course, the degrees of relevance will result in differences in reading. 


\section{Application of Relevance Theory in College English Teaching}

Relevance theory has a very important guiding role for English learners, especially the cultivation and improvement of college students' language practice and application ability. Applying relevance theory to the interaction between teachers and students in English classroom can bring some new enlightenment to English teaching [13].

\subsection{Improving Students' Cultural Realization}

Relevance theory emphasizes the mutual understanding and mutual understanding between the two parties and a person's cognitive ability is closely related to his social and cultural background. Different social and cultural backgrounds have derived from different cognitive structures and discourse expressions. Therefore, in a specific discourse and context, teachers should provide students with relevant background knowledge of specific texts, such as the background of the article writing, the purpose of writing. In this way teachers can help students to have a comprehensive grasp and understanding of the text, and get the best connection as soon as possible.

Moreover teachers can introduce some ways for students to broaden their background knowledge, such as watching movies, listening to the radio and reading extensively.

\subsection{Choose Reading Materials That Are Appropriate to Student's Knowledge Level}

When selecting materials for reading, teachers should select materials that are appropriate to the level of students' linguistic knowledge according to the actual situation. Teachers should also provide students with enough contextual information, so as to stimulate students' interest in reading and help students obtain a sense of reading accomplishment.

\subsection{Helping Students Understand Words Meaning in Reading Materials}

If the words are understood in strict accordance with the definition of the dictionary it is often impossible to accurately accept the information that the authors want to express in the process of reading and learning English. The use of relevance theory can fit some of the more vocabulary words into the understanding of the original theme, and then infer the true meaning that the author wants to express.

\subsection{Guiding Students to Find Optimal Relevance}

In pre-reading, teachers can pose some questions related to the text, introduction background knowledge. It is advantageous for teachers to apply multi-media to assist their teaching. During the process of reading, teachers can give cue words to students. In post-reading, teachers can design some true or false questions, filling in the missing information in the text diagram, writing a summary based on their understanding of the text.

\section{Conclusion}

In a word, Relevance Theory provides us with a new perspective to explore the nature of English reading and the ways to improve college English teaching. It is sincerely expected that the study can provide some indications and useful suggestions that will help improve the current college English teaching and call for more attentions to apply Relevance Theory guide such course as listening, speaking, and writing in college English teaching pedagogy.

\section{Acknowledgements}

1. The research is achievement of Social Science Fund of Shaanxi Province and Research Project on Major Theoretical and Practical Problems (2018C066); 2. The research is supported by Fundamental Research Fund for the Central Universities of China (3102017jc19006); 3. The research is supported by Degree and Graduate Education Research Fund of NPU (2018AC13).

\section{References}

[1] Krashen, S. D. The Input Hypothesis: Issues and Implications. New York: Longman, 1985.

[2] Jiao Meilian. On the Effective Development of Classroom Management in College English Grading Teaching Course Education Research, 2018 (23).

[3] Li Linpo. Study on Outdoor College English Teaching Mode [J]. Overseas English, 2016 (15), pp. 239.

[4] Li Silan. Problems in the Application of Task-based Language Teaching in English Class English on Campus, 2016 (34), pp. 59.

[5] Liao Daosheng. Cultural Barriers of Chinese EFL Learners in English Reading. Foreign Language Education, 2001 (4), pp. 72-77.

[6] Liu Dandan. A Study of Chinese EFL Learners' Reading Strategies. Foreign Language World, 2002 (6), pp. 13-18.

[7] Liu Yuhong. Application of Three-dimensional Teaching Mode in College English Teaching. Crazy English (Pro.), 2018 (2), pp. 123-124.

[8] Liu Zhenqian \& Thomas G. Bever. An experimental study of the function of syntactic analysis in reading comprehension. Foreign Language Teaching and Research, 2002 (3), pp. $219 / 240$.

[9] Song Zhenzhen. Study on the Teaching of English Reading Based on Relevance Theory. Journal of Nanchang College of Education, 2013 (03), pp. 138/140.

[10] Sperber D. \& Wilson D. Relevance: Communication and Cognition. Beijing: Foreign Language Teaching \& Research Press, 2001.

[11] Xiang Mingyou. Pragmatic Studies: A Mapping-Knowledge-Domain Analysis. Journal of Foreign Languages, 2015 (6), pp. 36. 
[12] Yan Ninglian \& Zhang Xiaoli. Teacher Roles in Humanistic Approaches. Shanxi Youth, 2017 (1), pp. 95-96.
[13] Zhang Zhi. Teacher Talk Code-switching in College English Teaching Classroom. Overseas English, 2016 (15), pp. 184-185. 